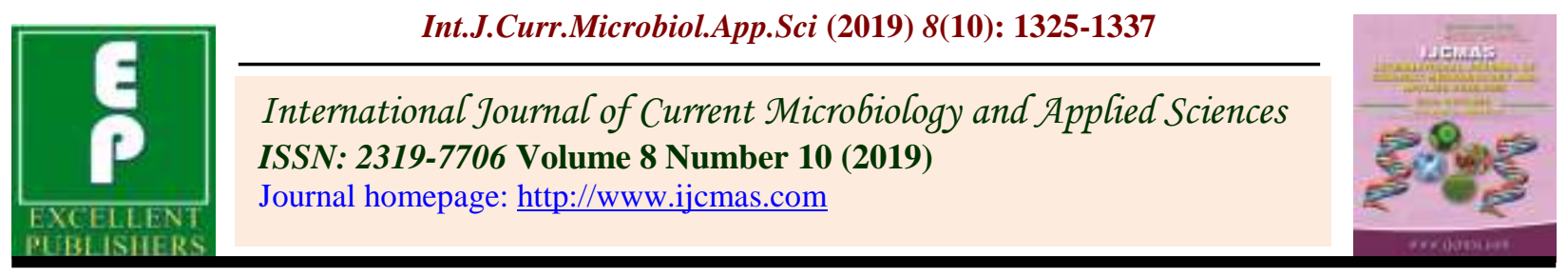

Original Research Article

https://doi.org/10.20546/ijcmas.2019.810.155

\title{
Use of Different Probability Distribution in Rainfall Analysis for RRS, Pundiari, Cooch Behar
}

\author{
Rakesh Kumar Meena, Sharda Dubey* and S. Basak \\ U.B.K.V. North Bengal, Pundibari, Cooch Behar, India \\ *Corresponding author
}

\section{A B S T R A C T}

\begin{tabular}{l} 
K e y w o r d s \\
Peak rainfall, \\
Probability \\
distributions, \\
Goodness-of-fit \\
tests \\
\hline Article Info \\
$\begin{array}{l}\text { Accepted: } \\
12 \text { September } 2019 \\
\text { Available Online: } \\
10 \text { October } 2019\end{array}$ \\
\hline
\end{tabular}

The daily rainfall data of 21 years were collected from the IMD approved Meteorological Observatory situated at Uttar Banga Krishi Viswavidyalaya, Pundibari, Cooch Behar, India. The data were then processed to identify the maximum rainfall received on any one day (24 hrs duration), in any week (7 days), in a month (4 weeks), in a monsoon season (4 months) and in a year (365 days period). The data showed that the annual daily maximum rainfall received at any time ranged between 134.5 (minimum) to $694.6 \mathrm{~mm}$ (Maximum) indicating a very large range of fluctuation during the period of study. The rainfall data were analysed to identify the best fit probability distribution for each period of study and the trend has been presented in this study. Three statistical goodness of fit test were carried out in order to select the best fit probability distribution on the basis of lowest rank with minimum value of test statistic. Five probability distribution was identified using maximum overall score based on sum of individual point score obtained from three selected goodness of fit test. The weibull and gamma distribution were best fitted distribution in the terai region. For entire period of study, gamma distribution was best fitted distribution in this region. Gamma distribution was observed in most of the weekly period as best fit probability distribution. The best fit probability distribution of monthly data was found to be different for each month. The scientific results clearly established that the analytical procedure devised and tested in this study may be suitably applied for the identification of the best fit probability distribution of weather parameters.

\section{Introduction}

Analysis of rainfall data strongly depends on its distribution pattern. It has long been a topic of interest in the fields of meteorology in establishing a probability distribution that provides a good fit to daily rainfall. Several studies have been conducted in India and abroad on rainfall analysis and best fit probability distribution function such as normal, log-normal, exponential, weibull and Gamma distribution were identified. Fisher (1924) studied the influence of rainfall on the yield of wheat in Rothamasted. He showed that it is the distribution of rainfall during a season rather than its total amount which influence the crop yield. Tippet (1929) subsequently applied the technique on 
sunshine distribution and found that sunshine has beneficial effect throughout the year on wheat crop. Another useful line of work relating to the study of rainfall distribution was introduced by Manning (1950). He transformed the skew frequency distribution of rainfall to approximate closely to the theoretical normal distribution. Moaley et al., (1972) studied statistical distribution of rainfall during south west and north east monsoon season at representative stations in India and Gamma distribution has been fitted to rainfall data. Bhargava et al., (1971) also showed that for a number of crops the distribution of rainfall over the season has a great influence on the yield. Upadhaya and Singh (1998) stated that it is possible to predict rainfall fairly accurate using various probability distributions for certain returns periods although the rainfall varies with space, time and have erratic nature. Baskar et al., (2006) observed the frequency analysis of consecutive days peaked rainfall at Banswara, Rajasthan, India, and found gamma distribution as the best fit as compared by other distribution and tested by Chi-square value. The present study is planned for establishing the methodology for identifying the pattern of probability distribution of weather parameter using least square method and the best fit probability distribution was evaluated on the basis of three goodness of fit test. The maximum rainfall data of a single site was used to select a best fit probability distribution for the value of weather parameters. Kulandaivelu (1984) analysed the daily precipitation data of Coimbatore for a period of 70 years for weekly totals by fitting incomplete Gamma distribution model.

The data indicate the likely commencement of rains, period of drought length of growing season and end of growing season. Based on the assured rainfall at (50\%) probability level, suitable cropping system was suggested for Coimbatore.
Biswas and Khambete (1989) computed the lowest amount of rainfall at different probability level by fitting gamma distribution probability model to week by week total rainfall of 82 stations in dry farming tract of Maharashtra. Chapman (1994) evaluated five daily rainfall generating models with several methods and analysed that SrikanthanMcMahon model performed well when calibrated with long rainfall records. Duan et al., (1995) suggested that for modeling daily rainfall amounts, the weibull and to a lesser extent the exponential distribution is suitable.

However recently it is observed that even in monsoon month (June to September) the crops are subjected to moisture /water stress due to occasional dry spells. Although, the total rainfall is high, its distribution is erratic making the crop vulnerable even during monsoon month. Lack of adequate amount of rainfall during the transplanting of Aman rice often affects the yield of the crop. Again heavy pre-monsoon rain affects the crop stand of jute. Hence, the farmer or agricultural planner must know the risk he is going to take in his endeavor. Any study using average rainfall or normal rainfall data cannot include this risk factor. This in turn calls for better understanding of rainfall probability characteristics to fit agro climatically suited cropping systems (Singandhupe et al., 2000). The Indian Summer Monsoon Rainfall season (ISMR), which plays a very important role in regulating the floods and droughts, regulates the crop yield, well being of the society, employment generation, and food insecurity. All this is related to the economy of the state and consequently of the country. Most of the agricultural crops are sensitive to their growing conditions especially rainfall and temperature which consequently comes under the key factors influenced by the climate change. It is easily predictable therefore, how variation and annual weather and changing climate may affect their production and 
growth. The effect on agriculture and its consequences on society are likely to differ locally depending on the type of climate change that has taken place in that area and the options available to the farmers. It may well bring new agricultural systems to the area and replace the old crop and farming systems. The abnormal pattern of rainfall over the past few years has caused great fluctuations in crop production. The performance of crops is directly related to rainfall received during the crop season. Water is required for all metabolic reactions in plant. Rainfall requirement at the time of sowing in rice crop is $1400-1800 \mathrm{~mm}$. The rainfall directly influenced the production as well as area sown under maize which showed positive correlation between them. When there was sufficient rainfall during the growing season of maize the production was high however during less rainfall, irregular and untimely rainfall there was decrease in production and area under the crop. The uncertainty about weather conditions is one of the key risk factors associated with crop production. The variation in rainfall is due to change in climate. Climate change influences the precipitation in many ways viz. change in rainfall pattern, frequency and intensity of rainfall etc. While there is general agreement that average temperatures will gradually increase, the distribution, frequency and intensity of changes in precipitation regimes are much more uncertain. From regional-level agronomic studies, large losses in wheat, rice and maize, among other crops, are projected for the 2050s. The scientific evidence on rainfall variability with its momentous impacts on crop yield is now stronger than ever. It is even more so on grains that serve as staple food in most parts of the world.

The report by World Meteorological Organization (WMO) revealed that the overall global warming is expected to add in one way or another to the difficulties of food production and scarcity. The report also stated that reduced availability of water resources would pose one of the greatest problems to agriculture and food production, especially in the developing countries. Meteorological drought indicates the deficiency of rainfall compared to normal rainfall in a given region over an extended period of time.

The impact of rainfall on crop production can be related to its total seasonal amount or its intra-seasonal distribution. In the extreme case of droughts, with very low total seasonal amounts, crop production suffers the most. But more subtle intra-seasonal variations in rainfall distribution during crop growing periods, without a change in total seasonal amount, can also cause substantial reductions in yields. This means that the number of rainy days during the growing period is as important, if not more, as that of the seasonal total. Jackson (1989) notes that even in wet locations rainfall variability at the daily time scale is critical to plant growth, particularly in the early part of the rainy season before soil moisture reserves have been built up. Generally, the effect of rainfall variability on crop production varies with types of crops cultivated, types and properties of soils and climatic conditions of a given area.

The aim of this study was to analyze rainfall variability at annual and seasonal time scales and examine vulnerability of food grain production to rainfall variability by using the Amhara region as a case study site. The specific objectives were to: i) examine local scale rainfall variability and trend by using data from a relatively dense network of stations, and ii) assess the magnitude of relationships between rainfall and crop production in the region.

Correlation and regression were used to examine relationships between monthly and seasonal rainfall and crop production. The 
patterns of inter-annual rainfall variability and fluctuations in cereal production are also presented graphically to gain a better insight into rainfall-crop production relationships in the region. It is important to note here that consideration of production of cereals will be more appropriate than yield in investigating the influence of rainfall variability, because the latter can miss out impacts of extreme climatic conditions involving severe droughts that might lead to abandonment of planted areas prior to harvest. In other words, total production aggregates impacts of climate on both production and yields and harvested areas and thus has greater economic relevance than yield. Further, amount and temporal distribution of rainfall also has influence on area cultivated in a given year.

The impact of rainfall on crop production can be related to its total seasonal amount or its intra-seasonal distribution. In the extreme case of droughts, with very low total seasonal amounts, crop production suffers the most. But more subtle intra-seasonal variations in rainfall distribution during crop growing periods, without a change in total seasonal amount, can also cause substantial reductions in yields. This means that the number of rainy days during the growing period is as important, if not more, as that of the seasonal total. Jackson (1989) notes that even in wet locations rainfall variability at the daily time scale is critical to plant growth, particularly in the early part of the rainy season before soil moisture reserves have been built up. Generally, the effect of rainfall variability on crop production varies with types of crops cultivated, types and properties of soils and climatic conditions of a given area.

There is positive correlation between the rainfall and the production as well as area sown under wheat crop which showed that rainfall is the major factor influencing the production as well as area sown under wheat in all districts. The area sown under the wheat was increasing or decreasing according to the occurrence of rainfall during the growing season of wheat.

Geographical distribution of rice growing areas in the world over regions of heavy rainfall in the relatively short period of the cropping season indicates that water supply is probably the chief limiting factor to the growth and production of rice. The pattern of frequency and depth of precipitation in different month of growing season would seem to have important physiological bearing of rice plants particularly relating to yield. The rice production and area sown under rice is positively correlated with the amount of rainfall received during the growing season of rice.

Ojo, et al., (2001) that the patterns of mean rain days generally follow the same pattern with mean rainfall amounts and that greater percentages of the rain days will be during the rainy season. Therefore, the concentration of rain days during rainy season is having a great influence on maize yield annually such that the higher and less evenly distributed the number of rain days the lower the maize yield. Maize requires a well-distributed, considerable amount of rainfall over an appropriate numbers of days during its growing season for optimum yield.

The rainfall directly influenced the production as well as area sown under maize which showed positive correlation between them. When there was sufficient rainfall during the growing season of maize the production was high however during less rainfall, irregular and untimely rainfall there was decrease in production and area under the crop.

The graphs show dramatic variations in all district in crop yield and cultivatable areas both with significant downward trend. The 
production has been on steady decline due to erratic rainfall variability and the area planted to maize has also been reduced to adapt to the anticipated drought period. The risk associated with climate variability of crop production in general depends mainly on the growth stage of the crop when the weather aberration occurs. The fluctuation in production of these major crops in Himachal Pradesh might be due to many factors but rainfall is the main factor that is affecting these crops to the maximum. The uncertainty about weather conditions is one of the key risk factors associated with crop production. The variation in rainfall is due to change in climate. Climate change influences the precipitation in many ways viz. change in rainfall pattern, frequency and intensity of rainfall etc. While there is general agreement that average temperatures will gradually increase, the distribution, frequency and intensity of changes in precipitation regimes are much more uncertain.

Mohan et al., suggest that the Variation of seasonal rainfall and probabilities of occurrence of assured weekly rainfall provide useful information for efficient agricultural management. In the present study, seven stations of Himachal Pradesh have been selected for the analysis of the rainfall data. In general, the station Dalhousie received the higher rainfall during both the growing and dormant seasons along with annual rainfall. Probability percentage of receiving $10 \mathrm{~mm}, 20$ $\mathrm{mm}, 50 \mathrm{~mm}$ and $75 \mathrm{~mm}$ rainfall have been computed for standard weeks during growing and dormant seasons at four stations Katrain, Bajaura, Mashobra and Nauni (Solan). A critical examination for spatial and temporal probability distribution revealed that high rainfall belt is located in the north western part of the state. For better apple production, monsoon rainfall plays significant role. It not only moderates the temperature during summer but also recharges the much-needed moisture, which almost depletes by mid June.
Well distributed winter rains and early snowfall before January are beneficial in providing chilling, optimal flowering and good fruit set.

\section{Materials and Methods}

The present study is based on time series data related to maximum daily rainfall annually, seasonally, monthly and weekly. The daily rainfall data of 21 years were collected from the IMD approved Meteorological Observatory situated at Uttar BangaKrishiViswavidyalaya, Pundibari, Cooch Behar, India. The dry season from October to May and wet season from June to September are found in terai region. The soils of terai region have good moisture holding capacities and have about $7.3 \mathrm{pH}$. The annual rainfall of this region is about $3200 \mathrm{~mm}$, which is subjected to large variation. The data were then processed to identify the maximum rainfall received on any one day (24hrs duration), in any week (7 days), in a month (4 weeks), in a monsoon season (4 months) and in a year (365 days period). The annual maximum daily rainfall is ranging from 134.5 $\mathrm{mm}$ to $694.6 \mathrm{~mm}$ during the study period as presented in Figure 1.

On an average the region monsoon rains occurring from June to September. More than $80 \%$ of the rain is received from south-west monsoon during four month period from June to September, and the rainfall of rainy season is significantly different from that of dry season. The best fit probability distribution was evaluated by using the following systematic steps.

\section{Step I: Fitting the probability distribution}

The probability distributions viz. normal, lognormal, gamma, weibull, exponential, were identified to evaluate the best fit probability distribution for rainfall. In addition the 
different forms of these distributions were applied to find out the best fit probability distribution.

The description of various probability distribution functions viz. density function, range and the parameter involved are presented in table 1 .

\section{Step: II. Test of goodness of fit}

Several testing measures are available in literature to test the comparability of the random sample with the theoretical probability distribution.

A few of them are Kolmogorov-Smirnov test, Anderson-Darling test, Chi-square test, variance ratio test suggested by Cochran (1954).We test fit of the distribution to the data under consideration using K-S test which is one of the most powerful test.

The goodness of fit test measures the compatibility of random sample with the theoretical probability distribution. The goodness of fit tests is applied for testing the following null hypothesis:

H0: the maximum daily rainfall data follow the specified distribution

H1: the maximum daily rainfall data does not follow the specified distribution.

The following goodness-of-fit tests viz. Kolmogorov-Smirnov test and AndersonDarling test were used along with the chisquare test at $\alpha(0.01)$ level of significance for the selection of the best fit Probability distribution.

\section{Kolmogorov-Smirnov test}

This statistical test defers from the chi-square test in the sense that it is done on cumulative
Distribution functions whereas the chi-square is done on probability distribution. This test is only applicable to continuous distribution functions. The Kolmogorov-Smirnov statistic (D) is defined as the largest vertical difference between the theoretical and the empirical cumulative distribution function (ECDF):

$\mathrm{D}=\{(x i) 1 \leq i \leq n \max -i-1 n, i n-\mathrm{F}(x i)\}$

Where $X i=$ random sample, $\mathrm{i}=1,2, \ldots \ldots \ldots \ldots$

$\operatorname{CDS}=(X)=1 n[$ Number of observations $\leq \mathrm{x}]$

This test is used to decide if a sample comes from a hypothesized continuous distribution.

The procedure for implementing the Kolmogorov-Smirnov test is as follows:

STEP 1. Let $F 0(x)$ be the sample cumulative distribution function based on Nobservations.

For any observed $x, F 0(x)=j N$ where $j$ is the number of observations lessthan or equal to $x$.

STEP 2. Let $F t(x)$ be the specified theoretical cumulative distribution function under the

Null hypothesis. Determine the maximum deviation, D, defined by

$\mathrm{D}=\max |F 0(x)-F t(x)|$

The hypothesis is rejected if, for the chosen significance level, the observed value of $\mathrm{D}$ is greater than or equal to the critical value of the Kolmogorov-Smirnov statistic.

\section{Anderson-Darling test}

The Anderson-Darling test is a member of a group of goodness-of-fit statistics which has come to be known as empirical distribution statistics (EDF) because they measure the 
discrepancy between the empirical distribution function of a given sample and the theoretical distribution to be tested.

The Anderson-Darling statistic (A2) is defined as

$$
\begin{array}{ll}
A 2 & =
\end{array}
$$

It is a test to compare the fit of an observed cumulative distribution function to an expected cumulative distribution function. This test gives more weight to the tails than the Kolmogorov-Smirnov test.

\section{Chi-Square test $\times 2(v)$}

The steps hereafter will be followed to make the chi-square test:

Step 1: put the observed data $(\mathrm{O})$ and expected (E) values into intervals so as to determine the Frequency of both variables in each class.

This can be well express by a histogram of frequencies.

Step 2: rearrange the classification so that the minimum expected frequency in each class Becomes 5 or great. The classes with low frequency should be merged to this end.

Step 3: compute the chi-square value for all intervals $\chi 2=\Sigma(O i-E i) 2 E i k i=1$

$\mathrm{V}$ is the degree of freedom and equals to $\mathrm{n}-\mathrm{k}-$ 1 , where $n$ is the number of intervals and $k$ is the number of distribution parameter obtained from the sample statistics; they are constraints imposed to the fitting process.

It is a test to compare the fit of an observed cumulative distribution function to an expected cumulative distribution function.
This test gives more weight to the tails than the Kolmogorov-Smirnov test.

\section{Step III: Identifying the best fit distribution}

The three goodness of fit test mentioned above were fitted to the maximum rainfall data treating different data set. The test statistic of each test were computed and tested at $(\alpha=0.01)$ level of significance. Accordingly the ranking of different probability distributions were marked from 1 to 16 based on minimum test statistic value. The distribution holding the first rank was selected for all the three tests independently. The assessments of all the probability distribution were made on the bases of total test score obtained by combining the entire three tests. The total score of the entire three tests were summarized to identify the best fit distribution on the bases of lowest score obtained.

Finally the best fit probability distributions for maximum rainfall on different sets of data were obtained and the best fit distribution for each set of data was identified. The above methodology can also be used for studying the probability distribution pattern for other weather variable.

\section{Results and Discussion}

The methodology presented above was applied to the 21 years weather data in which maximum rainfall in $\mathrm{mm}$. were taken from meteorological observatory, Pundibari. Accordingly, these 21 data sets were classified as year wise best fit distribution and parameter estimate to study period at RRS, Pundibari (Table 2).

The summary of wise best fitted distribution and parameter estimate during study period 1995-2015 and date wise \& week wise maximum rainfall for different years along with monthly maximum rainfall and weekly 
best fit distribution \& its parameter estimates are table 3, 4 and 5 respectively. Where, the mean of maximum daily rainfall of all years annually is $420 \mathrm{~mm}$, minimum daily rainfall is $0.52 \mathrm{~mm}$ and monthly it is ranging from 4.35 to $662.50 \mathrm{~mm}$.

The maximum daily rainfall in a year/monsoon season is $743.48 \mathrm{~mm}$ and monthly maximum daily rainfall in monsoon season is ranging from 471.92 to $743.48 \mathrm{~mm}$.

The observed trend, gradual and consistent increase from January to April followed by a sudden \& sharp increase in May \& June. It peaks in July and thereafter a slight drop in
August. Thereafter there is a sudden and sharp drop in rainfall in the months of September \& October followed by nearly no rain in the months of November \& December.

The month of July records the highest monthly average rainfall $743.48 \mathrm{~mm}$ or $22 \%$ of total annual rainfall. Whereas the month of November records the lowest monthly average rainfall $6.45 \mathrm{~mm}$ or $0.1 \%$ of total annual rain closely followed by December at $4.25 \mathrm{~mm}$ or $0.1 \%$ of annual total. The variation is $50 \%$ or less in the rainfall months of May to September. However in the months of scanty rain i.e. October to April the variation is more indicating an erratic rainfall month (Fig. 1-3).

Table.1 Description of various probability distribution functions

\begin{tabular}{|c|c|c|c|}
\hline Distribution & PDF & Range & parameters \\
\hline $\begin{array}{c}\text { Gamma } \\
(2 \mathrm{P})\end{array}$ & $\begin{array}{c}\mathbf{F}(\mathbf{x})=x \propto-1 \beta \alpha \Gamma \alpha \exp \langle- \\
(x) / \beta\rangle\end{array}$ & $\boldsymbol{\gamma} \leq \boldsymbol{x}<+\infty$ & $\begin{array}{c}\alpha=\text { Shape } \\
\text { parameter }(\alpha>0) \\
\beta=\text { Scale } \\
\text { parameter }(\beta>0) \\
\gamma=\text { location parameter } \\
\text { yields two para the } \\
\text { tw } \Gamma=\text { Gamma Function }\end{array}$ \\
\hline Log normal (2P) & $\begin{array}{c}\mathrm{F}(\mathrm{x})= \\
\exp [-1 / 2(\operatorname{In}(x)-\mu / \sigma) 2 \\
](x) \sigma \sqrt{2 \pi}\end{array}$ & $\boldsymbol{\gamma} \leq \boldsymbol{x}<+\infty$ & $\begin{array}{c}\alpha=\text { Shape } \\
\text { parameter }(\alpha>0) \text { s } \\
\beta=\text { Scale } \\
\text { parameter }(\beta>0) \\
\gamma=\text { location parameter } \\
\text { yields the twtwo par }\end{array}$ \\
\hline Normal & $\begin{array}{c}F(x)=1 \sigma \sqrt{ } 2 \pi \exp [- \\
1 / 2(x-\mu) 2 \sigma 2]\end{array}$ & $-\infty \leq \boldsymbol{x}<+\infty$ & $\begin{array}{c}\mu=\text { Mean } \sigma=\text { Standard } \\
\text { deviation }(\sigma>0)\end{array}$ \\
\hline Weibull & $\begin{array}{c}\mathbf{F}(\mathbf{x})=\propto \\
\alpha \boldsymbol{\beta}((\boldsymbol{x} / \boldsymbol{\beta}) \boldsymbol{\alpha}-1 \exp [ \\
-(x / \boldsymbol{x}) \alpha]\end{array}$ & $\boldsymbol{\gamma} \leq \boldsymbol{x}<+\infty$ & $\begin{array}{c}\alpha=\text { Shape } \\
\text { parameter }(\alpha>0) \\
\beta=\text { Scale } \\
\text { parameter }(\beta>0) \\
\gamma=\text { location parameter } \\
\text { yields the twwo par }\end{array}$ \\
\hline
\end{tabular}


Table.2 Best fitted distribution and parameter year-wise

\begin{tabular}{|c|c|c|}
\hline YEAR & Best fit Distribution & Parameter \\
\hline 1995 & Gamma & $\alpha=0.48772 \beta=239.85$ \\
\hline 1996 & Gamma & $\alpha=0.59529 \quad \beta=190.09$ \\
\hline 1997 & Weibull & $\alpha=0.53681 \quad \beta=58.779$ \\
\hline 1998 & Gamma & $\alpha=0.74914 \beta=161.35$ \\
\hline 1999 & Gamma & $\alpha=0.8157 \quad \beta=172.88$ \\
\hline 2000 & Lognormal & $\alpha=1.3791 \quad \beta=3.8863$ \\
\hline 2001 & Weibull & $\alpha=0.58727 \quad \beta=83.639$ \\
\hline 2002 & Gamma & $\alpha=0.66309 \quad \beta=121.4$ \\
\hline 2003 & Weibull & $\alpha=0.56535 \quad \beta=72.473$ \\
\hline 2004 & Weibull & $\alpha=0.76297 \quad \beta=85.969$ \\
\hline 2005 & Gamma & $\alpha=0.78037 \quad \beta=120.8$ \\
\hline 2006 & Gamma & $\alpha=0.52804 \beta=131.62$ \\
\hline 2007 & Gamma & $\alpha=0.67581 \quad \beta=118.75$ \\
\hline 2008 & Gamma & $\alpha=0.71235 \quad \beta=153.71$ \\
\hline 2009 & Gamma & $\alpha=0.96824 \beta=94.467$ \\
\hline 2010 & Weibull & $\alpha=0.66646 \beta=46.101$ \\
\hline 2011 & Weibull & $\alpha=0.64819 \quad \beta=71.71$ \\
\hline 2012 & Weibull & $\alpha=0.62111 \quad \beta=83.589$ \\
\hline 2013 & Weibull & $\alpha=0.74898 \quad \beta=58.599$ \\
\hline 2014 & Gamma & $\alpha=0.69251 \quad \beta=98.959$ \\
\hline 2015 & Gamma & $\alpha=0.90729 \quad \beta=91.806$ \\
\hline
\end{tabular}

Table.3 Score wise best fitted distribution and parameter estimate during study period 19952015

\begin{tabular}{|c|c|c|c|c|c|c|}
\hline Sr.No. & $\begin{array}{c}\text { Best Fit } \\
\text { distribution }\end{array}$ & $\begin{array}{c}\text { Score } \\
\text { Rank }\end{array}$ & parameter estimate & \multicolumn{3}{|c|}{ Statistic } \\
\cline { 5 - 7 } & & & & $\begin{array}{c}\text { Kolmogorov } \\
\text { Smirnov }\end{array}$ & $\begin{array}{c}\text { Anderson } \\
\text { Darling }\end{array}$ & $\begin{array}{c}\text { Chi- } \\
\text { Square }\end{array}$ \\
\hline $\mathbf{1 .}$ & Gamma & 4 & $\alpha=0.66343 \beta=140.29$ & 0.03843 & 2.1812 & 34.624 \\
\hline $\mathbf{2 .}$ & Weibull & 5 & $\alpha=0.67446 \beta=79.101$ & 0.06559 & 3.0505 & 28.505 \\
\hline $\mathbf{3 .}$ & Lognormal & 10 & $\sigma=1.8591 \mu=3.5244$ & 0.13382 & 18.71 & 110.9 \\
\hline $\mathbf{4 .}$ & Exponential & 11 & $\lambda=0.01074$ & 0.12124 & 30.843 & 126.06 \\
\hline $\mathbf{5 .}$ & Normal & 15 & $\sigma=114.27 \mu=93.072$ & 0.20793 & 52.63 & 154.5 \\
\hline
\end{tabular}


Table.4 Date wise \& week wise maximum rainfall for different years along with monthly maximum rainfall

\begin{tabular}{|c|c|c|c|c|c|}
\hline Year & $\begin{array}{c}\text { Week } \\
\text { No }\end{array}$ & $\begin{array}{c}\text { Date of } \\
\text { rainfall }\end{array}$ & $\begin{array}{c}\text { Maximum } \\
\text { rainfall(mm) }\end{array}$ & $\begin{array}{c}\text { Name of } \\
\text { month }\end{array}$ & $\begin{array}{c}\text { Monthly Maximum } \\
\text { rainfall(mm) }\end{array}$ \\
\hline $\mathbf{1 9 9 5}$ & 33 & 15.08 .1995 & 183.9 & August & 1061.9 \\
\hline $\mathbf{1 9 9 6}$ & 28 & 13.07 .1996 & 101.8 & July & 1193.2 \\
\hline $\mathbf{1 9 9 7}$ & 24 & 09.7 .1997 & 136 & August & 1059.2 \\
\hline $\mathbf{1 9 9 8}$ & 36 & 3.9 .1998 & 284.9 & August & 948.9 \\
\hline $\mathbf{1 9 9 9}$ & 28 & 10.7 .1999 & 474 & July & 1274.4 \\
\hline $\mathbf{2 0 0 0}$ & 27 & 06.07 .2000 & 196.3 & June & 981.1 \\
\hline $\mathbf{2 0 0 1}$ & 34 & 22.08 .2001 & 132.3 & September & 760.5 \\
\hline $\mathbf{2 0 0 2}$ & 29 & 20.07 .2002 & 200 & July & 1107.2 \\
\hline $\mathbf{2 0 0 3}$ & 26 & 26.07 .2003 & 96.2 & June & 935.9 \\
\hline $\mathbf{2 0 0 4}$ & 29 & 11.07 .2004 & 86.6 & July & 1190.9 \\
\hline $\mathbf{2 0 0 5}$ & 25 & 18.07 .2005 & 53 & August & 778.5 \\
\hline $\mathbf{2 0 0 6}$ & 27 & 28.07 .2006 & 160 & September & 506.5 \\
\hline $\mathbf{2 0 0 7}$ & 36 & 30.08 .2007 & 47.8 & July & 618.3 \\
\hline $\mathbf{2 0 0 8}$ & 35 & 30.08 .2008 & 239.6 & August & 1172.7 \\
\hline $\mathbf{2 0 0 9}$ & 26 & 23.06 .2009 & 116.8 & June & 540.3 \\
\hline $\mathbf{2 0 1 0}$ & 30 & 23.07 .2010 & 39.6 & August & 360.2 \\
\hline $\mathbf{2 0 1 1}$ & 38 & 18.9 .2011 & 214.60 & July & 800.4 \\
\hline $\mathbf{2 0 1 2}$ & 28 & 11.7 .2012 & 65.60 & July & 739.8 \\
\hline $\mathbf{2 0 1 3}$ & 28 & 10.7 .2013 & 203.20 & July & 682.7 \\
\hline $\mathbf{2 0 1 4}$ & 23 & 8.6 .2014 & 128.90 & June & 604.3 \\
\hline $\mathbf{2 0 1 5}$ & 35 & 02.09 .2015 & 88.90 & August & 797.3 \\
\hline & & & & & \\
\hline
\end{tabular}

Fig.1 Year wise annual maximum daily rainfall (in $\mathrm{mm}$ )

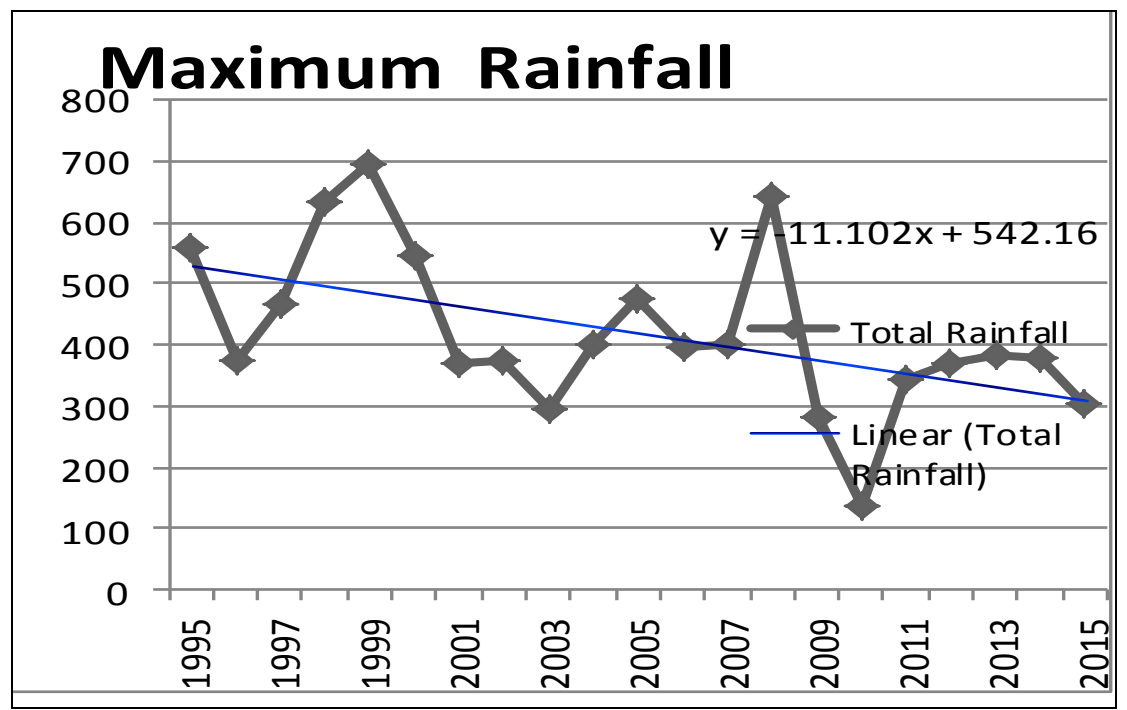


Table.5 Weekly best fit distribution \& its parameter estimates

\begin{tabular}{|c|c|c|}
\hline Week no & Best fit dist & Parameter estimate \\
\hline 10 & Log- logistic & $\alpha=0.82435 \quad \beta=0.70477$ \\
\hline 11 & Log normal & $\sigma=1.8401 \mu=1.3782$ \\
\hline 12 & Log normal & $\sigma=1.9756 \mu=1.5481$ \\
\hline 13 & weibull & $\alpha=0.64761 \quad \beta=31.478$ \\
\hline 14 & Log- logistic & $\alpha=1.9269 \quad \beta=26.758$ \\
\hline 15 & Gamma & $\alpha=1.3114 \beta=17.587$ \\
\hline 16 & Gamma & $\alpha=1.9469 \quad \beta=21.41$ \\
\hline 17 & Normal & $\sigma=35.96 \mu=47.853$ \\
\hline 18 & weibull & $\alpha=0.87393 \quad \beta=61.01$ \\
\hline 19 & Gamma & $\alpha=1.7363 \quad \beta=30.057$ \\
\hline 20 & Normal & $\sigma=47.487 \mu=57.9$ \\
\hline 21 & Log normal & $\sigma=0.77245 \mu=4.3988$ \\
\hline 22 & Normal & $\sigma=77.307 \mu=127.54$ \\
\hline 23 & weibull & $\alpha=1.2027 \quad \beta=142.82$ \\
\hline 24 & Exponential & $\lambda=0.00681$ \\
\hline 25 & weibull & $\alpha=1.3152 \beta=225.7$ \\
\hline 26 & Log normal & $\sigma=0.76464 \mu=4.7152$ \\
\hline 27 & Gamma & $\alpha=1.7926 \beta=109.41$ \\
\hline 28 & Exponential & $\lambda=0.00465$ \\
\hline 29 & Gamma & $\alpha=0.86931 \quad \beta=168.96$ \\
\hline 30 & Exponential & $\lambda=0.0081$ \\
\hline 31 & Gamma & $\alpha=1.3447 \quad \beta=69.256$ \\
\hline 32 & weibull & $\alpha=1.0134 \beta=110.85$ \\
\hline 33 & Exponential & $\lambda=0.00502$ \\
\hline 34 & Log normal & $\sigma=1.0367 \mu=4.5407$ \\
\hline 35 & Log- logistic & $\alpha=1.8568 \beta=83.408$ \\
\hline 36 & weibull & $\alpha=0.82011 \quad \beta=116.61$ \\
\hline 37 & Gamma & $\alpha=0.98831 \quad \beta=88.867$ \\
\hline 38 & Gamma & $\alpha=0.79016 \quad \beta=142.86$ \\
\hline 39 & Gamma & $\alpha=1.9844 \beta=51.608$ \\
\hline 40 & Exponential & $\lambda=0.01568$ \\
\hline 41 & Exponential & $\lambda=0.01422$ \\
\hline 42 & Log- logistic & $\alpha=0.86575 \beta=11.066$ \\
\hline
\end{tabular}


Fig.2 Year wise annual Minimum daily rainfall (in mm)

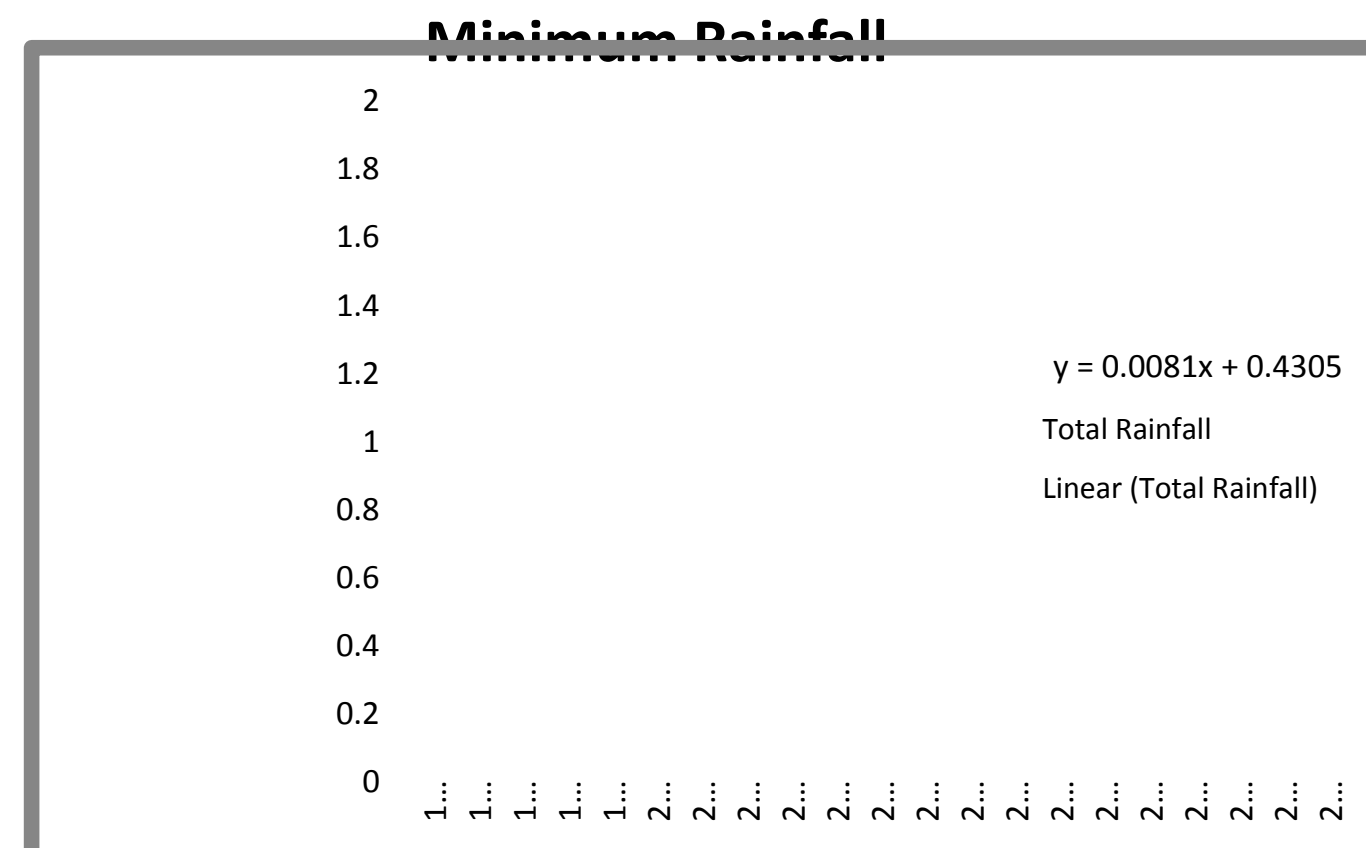

Fig.3 Density graph of Gamma distribution

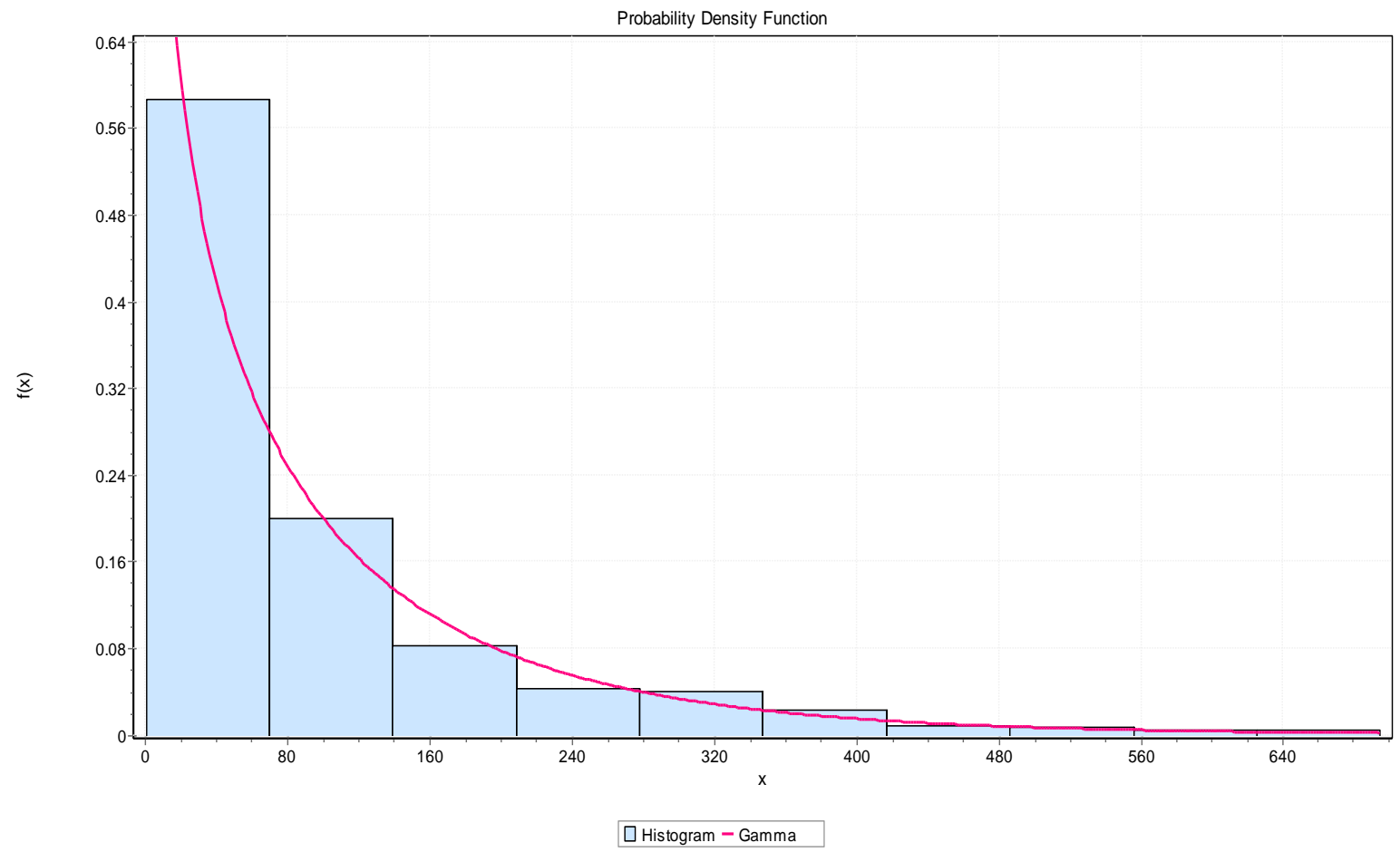




\section{References}

Bhakar, S.R., Bansal, A.N., Chhajed, N., and Purohit, R.C. (2006)., Frequency analysis of consecutive day's maximum rainfall at Banswara, Rajasthan, India. ARPN Journal of Engineering and Applied Sciences. PP. 64-67.

Bhargava, P.N. (1974)., The influence of rainfall on crop production. Research Journal of JawaharLal Nehru KrishiVishwavidyalaya.32, No. 1 and 2.

Biswas, B.C. and Khambeta, N.K. Distribution of short period rainfall over dry farming tract of Maharashtra. Journal of Maharashtra Agricultural University. 1989.

Chapam, T. Stochastic models for daily rainfall. The Institution of Engineers, Australia, National Conference Publication. 1994;94 (15): 7-12.

Fisher R.A.(1924) The influence of the rainfall on the yield of wheat at Rothamsted. Philosophical transaction of the Royal Society of London.Series B, Vol. 213.

Jackson, I. J. 1989. Climate, water and agriculture in the tropics.Longman Scientific and Technical, New York, USA.

Manning, H.L. Confidence limits of monthly rainfall. Jour, Agril. Sci. 1950;40: 169.
Moaley, D.A. (1972) "Gamma distribution probability model for Asian Summer Monsoon monthly rainfall.” Monthly weather Review 1972 vol.101, No.2.

Ojo, O., Ojo, K. and Oni, F. 2001. Fundamentals of Physical and Dynamic Climatology. SESEC Publishers, Lagos, Nigeria.

Sharma, Mohit Anand and Singh, Jai Bhagwan (2010). "Use of Probability Distribution in Rainfall Analysis". New york science journal;3(9).

Singandhupe, R.B., Anand P.S.B. and Kannan K. (2000).Effects of rainfall pattern on rice productivity in state of Orissa. Crop research, 20(3): 360-366.

Singh, Mohan., Kumar Jayant., Bhardwaj, S.S., 'Rainfall probability during dormant and growing seasons of apple in Himachal Pradesh" Regional horticultural research station, Dr. YS Parmar University of Horticulture \& Forestry, Seobag, PO Neoli-175138, Kullu (HP).

Tippet, L.H.C. On the effect of sunshine on wheat yield at Rothamsted. Jour. Agril. Sci. 1929;60, 2.

Upadhaya, A., and Singh, S.R. Estimation of consecutive day's maximum rainfall by various methods and their comparison. Indian Journal of S. Cons. 1998; 26 (2): 193-2001.

\section{How to cite this article:}

Rakesh Kumar Meena, Sharda Dubey and Basak, S. 2019. Use of Different Probability Distribution in Rainfall Analysis for RRS, Pundiari, Cooch Behar. Int.J.Curr.Microbiol.App.Sci. 8(10): 1325-1337. doi: https://doi.org/10.20546/ijcmas.2019.810.155 